\title{
The Use of Chloranilic Acid for the Spectrophotometric Determination of Three Macrolides through Charge Transfer Complex
}

\author{
Najma Sultana1, Saeed Arayne $\mathbf{M}^{2}$ and Saeeda Nadir Ali²* \\ ${ }^{1}$ Department of Pharmaceutical Chemistry, Faculty of Pharmacy, University of Karachi, Karachi-75270, Pakistan
}

${ }^{2}$ Department of Chemistry, University of Karachi, Karachi-75270, Pakistan

\begin{abstract}
In the present study, simple and fast spectrophotometric method have been reported for the determination of three macrolides i.e., erythromycin, roxithromycin and clarithromycin through charge transfer complexes. The method involves the interaction of macrolides with chloranilic acid in acetonitrile medium. Stoichiometry was found to be 1:1 for all the complexes. Under the optimized conditions, the complexes were found to be absorbed at 498, 496 and $491 \mathrm{~nm}$ with in the linearity range of 3-36, 4-40 and 8-40 $\mathrm{g} \mathrm{m} \mathrm{mL}^{-1}$ with minimum detection limit 190, 600 and $370 \mathrm{ng}$ $\mathrm{mL}^{-1}$ for respectively. The corresponding molar absorptivity values were determined to be $2.07 \times 10^{4}, 1.81 \times 10^{4}$ and $1.67 \times 10^{4} \mathrm{Mol}^{-1} \mathrm{~cm}^{-1}$ respectively. The data is discussed in terms of oscillator's strength, dipole moment, ionization potential, energy of complexes, resonance energy, association constant and Gibb's free energy changes. BenesiHildebrand plots for all complexes have been constructed. Furthermore, the methods were successfully applied for the determination of studied macrolides in pharmaceutical formulations. The interday and intraday precision and percent recovery values were evaluated. Results of analysis were validated successfully. Commonly present excipients did not show interference during analysis.
\end{abstract}

Keywords: Charge transfer complexes; Macrolides; Chloranilic acid; Benesi-Hildebrand plots

\section{Introduction}

Macrolides (Figure 1), a broad spectrum antibiotic drugs, belong to polyketide class of natural products, consisting of usually 14, 15 or 16-membered macrocyclic lactone ring attached with one or more deoxy sugars, usually cladinose and desosamine. They are primarily used against gram-positive cocci and intracellular pathogens such as mycoplasma, chlamydia, campylobacter, legionella and prescribed to treat infections of the respiratory tract, genital, gastrointestinal tract and soft tissue infections which occur by strains of bacteria susceptible to this class of antibiotics. Macrolides are the less toxic preparations among other antibacterial drugs [1].

Various analytical methods have been reported for the

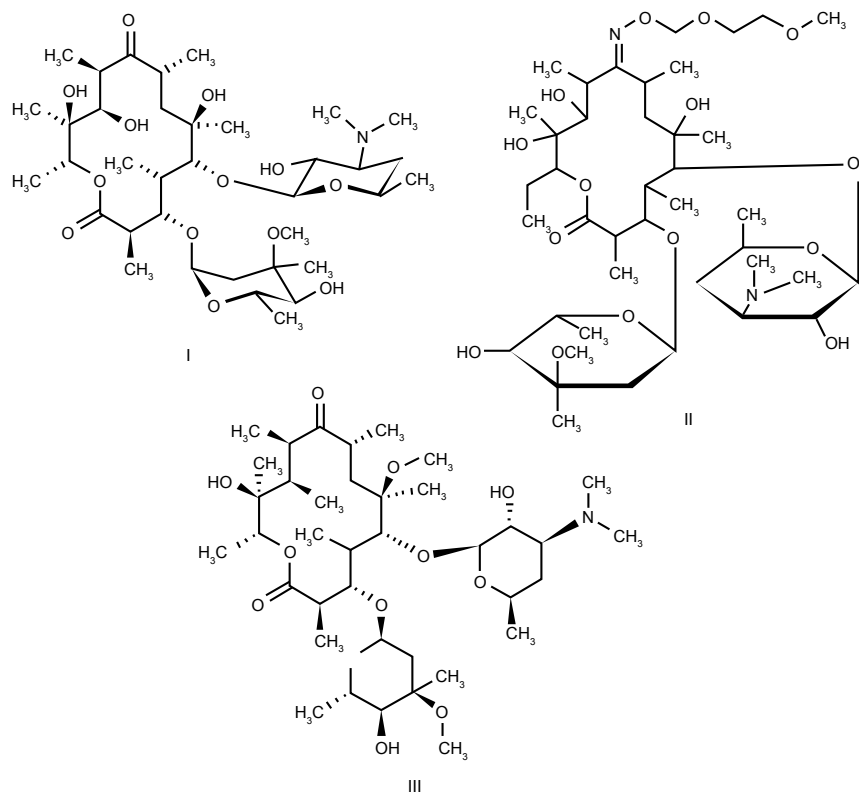

Figure 1: Chemical structures of (I) ERY, (II) ROX and (III) CLR. determination of studied macrolides. Flurer reported the determination of erythromycin (ERY) and clarithromycin (CLR) by capillary electrophoresis [2]. Lalloo et al. reported the separation of ERY with other macrolides by capillary electrophoresis [3]. The have been determined by Spectrofluorimetry [4,5], liquid chromatography [6-9] by near infrared reflectance (NIR) spectroscopy [10,11]. A number of spectrophotometric methods have also been employed for the determination of macrolides [12]. ERY has been determined using 1, 2-naphthoquinone-4-sulphonate [13], gentiana violet [14] CLR has been determined spectrophotometrically by using bromothymol blue and cresol red [15], p-dimethylamino benzaldehyde [16]. Recently a review article has been published by Bekeke and Gebeyehu describing the reported analytical methods and microbial assay for the determination of studied macrolides [1].

In the last decade, a number of spectrophotometric methods for the determination of verapamil [17], gabapentin [18], quinolone antibiotics [19], metformin [20], ascorbic acid [21] and montelukast [22] have been developed by our research fellows. In the present study we aimed to describe the rapid and accurate spectrophotometric methods for the determination of three macrolides; ERY, roxithromycin (ROX) and CLR. Since macrolides do not have sufficient chromophoric groups, which enable this group of compound to be determined directly by spectrophotometer, therefore the analysis has been carried out by charge transfer complexes of these macrolides with chloranilic acid (ChA). The optimum reaction conditions of the developed methods have been established, besides, the oscillator strength (f), dipole moment $(\mu)$, ionization potential $\left(\mathrm{I}_{\mathrm{p}}\right)$, energy of charge transfer complex $\left(\mathrm{E}_{\mathrm{CT}}\right)$ and resonance energy $\left(\mathrm{R}_{\mathrm{N}}\right)$ and also the association constant $\left(\mathrm{K}_{\mathrm{c}}\right)$ and

*Corresponding author: Saeeda Nadir Ali, Department of Chemistry, University of Karachi, Karachi-75270, Pakistan, E-mail: saeeda_khowaja@hotmail.com

Received June 13, 2013; Accepted July 25, 2013; Published July 27, 2013

Citation: Sultana N, Saeed Arayne M, Ali SN (2013) The Use of Chloranilic Acid for the Spectrophotometric Determination of Three Macrolides through Charge Transfer Complex. Med chem 3: 241-246. doi:10.4172/2161-0444.1000146

Copyright: $\odot 2013$ Sultana N, et al. This is an open-access article distributed under the terms of the Creative Commons Attribution License, which permits unrestricted use, distribution, and reproduction in any medium, provided the original author and source are credited. 
standard free energy changes $\left(\Delta \mathrm{G}^{\circ}\right)$ have been evaluated. Furthermore, the method was successfully applied for the determination of studied macrolides in pharmaceutical formulations. Excipients of formulations did not found to interfere in the assay of macrolides in pharmaceutical formulations.

\section{Experimental}

\section{Materials and reagents}

Pure ERY and CLR were obtained from Abbott Laboratories Pakistan Ltd and ROX was a kind gift from Aventis Pharma Pakistan Ltd. Erythrocin ${ }^{\circledR} 100 \mathrm{mg}$ tablets (Abbott Laboratories Pakistan Ltd), Rithmo $^{\circledR} 250 \mathrm{mg}$ (Sami Pharmaceuticals (PVT) Ltd) and Claritek ${ }^{\circledR}$ $250 \mathrm{mg}$ (Getz Pharma Pakistan (PVT) Ltd) were purchased from local market. ChA was purchased from Merck Schuchardt OHG, Darmstadt, Germany. Analytical grade acetonitrile was used throughout.

\section{Instrument}

Shimadzu model 1800 double beam UV-visible spectrophotometer provided with $1 \mathrm{~cm}$ quartz cells connected with Pentium IV computer loaded with version 2.32 software.

\section{Stock standard solutions}

$1 \mathrm{mg} \mathrm{mL} \mathrm{m}^{-1}$ stock solution of each drug was separately prepared in analytical grade acetonitrile. Working standard solutions were prepared by further dilution of these solutions with same solvent. $0.1 \%$ ChA solution was prepared in acetonitrile.

\section{Calibration curves}

Serial volumes of stock solutions ranging from $0.3-3.6,0.8-4.0$ and 0.4-4.0 mL ERY, ROX and CLR were transferred to $10 \mathrm{ml}$ volumetric flasks. To each flask $0.5 \mathrm{ml} \mathrm{ChA} \mathrm{was} \mathrm{added} \mathrm{and} \mathrm{the} \mathrm{volume} \mathrm{was} \mathrm{brought}$ to mark by adding acetonitrile. The absorbance was measured against reagent blank prepared similarly. Calibration graph in each case was prepared by plotting absorbance vs. concentration of each macrolides.

\section{Pharmaceutical formulation}

Twenty tablets of each formulation were separately weighed and finely powdered into pestle and mortar. An accurately weighed portion of powder equivalent to $100 \mathrm{mg}$ of drug was dissolved in acetonitrile and shaken well for proper mixing. The contents were allowed to stand for $30 \mathrm{~min}$ and then sonicated for complete extraction of drugs. The residue were filtered and washed. Finally, the volume was made up to $100 \mathrm{~mL}$ with same solvent. The measurements were carried out according to the procedure described under the preparation of calibration graphs.

\section{Results and Discussion}

\section{Absorbance spectra}

Macrolides belongs to an interesting drug class called antibiotics. They are reported to take part in many of the chemical reactions $[23,24]$. In the present study, we aimed to develop charge transfer complexes of macrolides with ChA. ChA showed strong red color, giving maximum absorbance at $430 \mathrm{~nm}$ in the acetonitrile medium [25]. The interaction of studied macrolides with $\mathrm{ChA}$ show wavelength apart from reagents alone. The newly formed complexes showed pink color for ERY and CLR and light purple color for ROX which gives absorption maxima at 498, 496 and $491 \mathrm{~nm}$ respectively against reagent blank prepared under identical conditions. Figure 2 represents the electronic absorption spectra of complexes and the proposed reaction is illustrated in Scheme 1.

\section{Optimization of experimental conditions}

In order to establish the optimum reaction conditions suitable for the complexation, various analytical parameters were studied. The effect of each parameter was observed by altering one parameter at a time while keeping others constant. A number of analytical solvents were checked like methanol, acetonitrile, dichloromethane, acetone, dimethyl sulfoxide and water, acetonitrile was found to give high sensitivity and maximum absorbance. To study the optimum reaction time the absorbance of complexes were measured $0,2,5$ and $10 \mathrm{~min}$. It was noticed that complete color development was achieved instantaneously at ambient temperature $\left(25 \pm 2^{\circ} \mathrm{C}\right)$ and there was no effect on absorbance at different time interval (Figure 3 ). The formed color complexes were found to be stable for $24 \mathrm{~h}$ for all three complexes. To determine the effect of ChA concentration, the concentration of each macrolides was kept constant and the concentration of ChA was varied by varying the $\mathrm{mL}$ of stock solution. Above $0.28,0.24$ and 0.27 $\mathrm{mL}$ of ChA for ERY, ROX and CLR respectively, there was no effect on absorbance of complex, therefore, $0.5 \mathrm{~mL}$ ChA was found to be sufficient for complete complexation (Figure 4).

\section{Stoichiometric ratio of complexes}

The stoichiometric ratio of macrolides and ChA was established by applying Job's method of continuous variation using equimolar

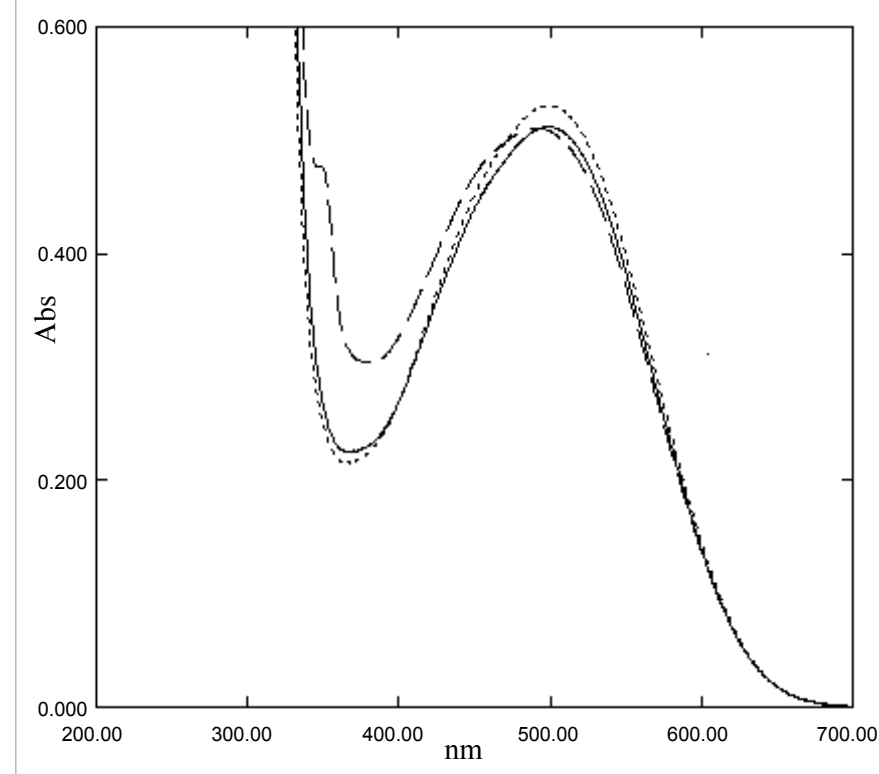

Figure 2: UV Spectra of ERY (-), ROX (...) and CLR (---).

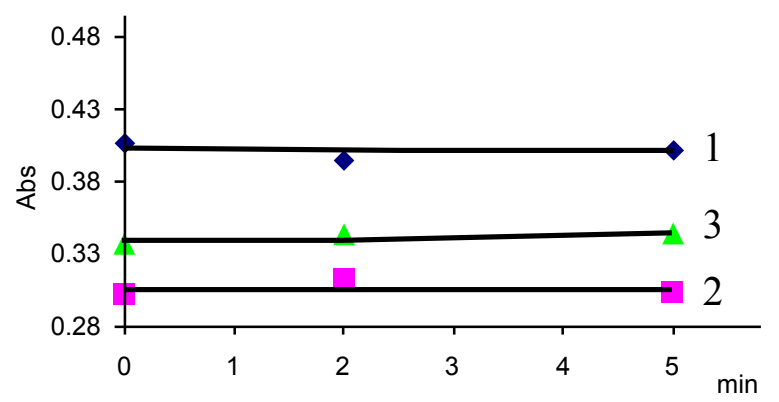

Figure 3: Effect of time on ChA complexation with (1) ERY $\left(15 \mu \mathrm{gL}^{-1}\right)$, (2) $\operatorname{ROX}\left(14 \mu \mathrm{g} \mathrm{mL}^{-1}\right)$ and $(3) \operatorname{CLR}\left(16 \mu \mathrm{gL}^{-1}\right)$. 
solutions [26] by taking absorbance of complex solutions of different ratios $(0: 10,1: 9, \ldots \ldots . .10: 0)$ (donor:acceptor). The graph was plotted between the mole fractions of each drug vs. absorbance. Figure 5 indicates that all the macrolides interacted with $\mathrm{ChA}$ in stoichiometric ratio of 1:1.

\section{Linearity, accuracy and precision}

Under the described analytical conditions, standard calibration curves for each macrolides with ChA were constructed over the range 3-36, 4-40 and 8-40 $\mu \mathrm{g} \mathrm{mL}^{-1}$ for ERY, ROX and CLR respectively by plotting absorbance verses concentration of drug. The correlation coefficient in each case is greater than 0.998 indicating good linearity. The corresponding molar absorptivity values have been calculated, which were determined to be $2.07 \times 10^{4}, 1.81 \times 10^{4}$ and $1.67 \times 10^{4} \mathrm{Mol}^{-1}$ $\mathrm{cm}^{-1}$ respectively. Linearity, correlation coefficient, slope, intercept,

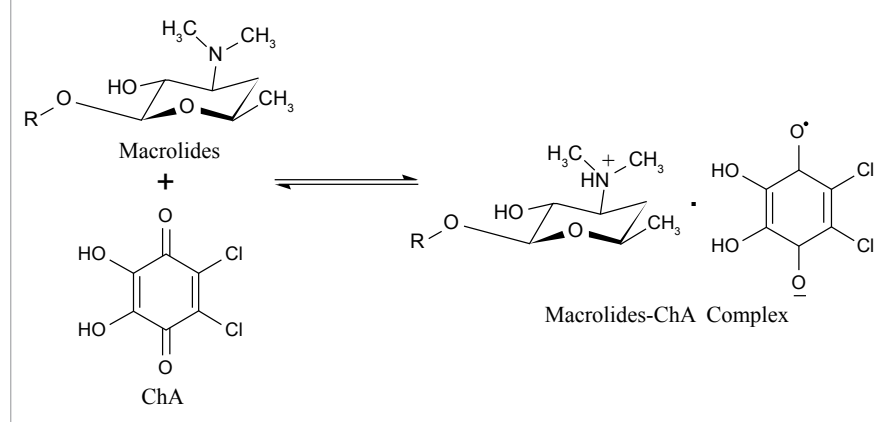

Scheme 1: Schematic diagram of reaction of macrolides with ChA.

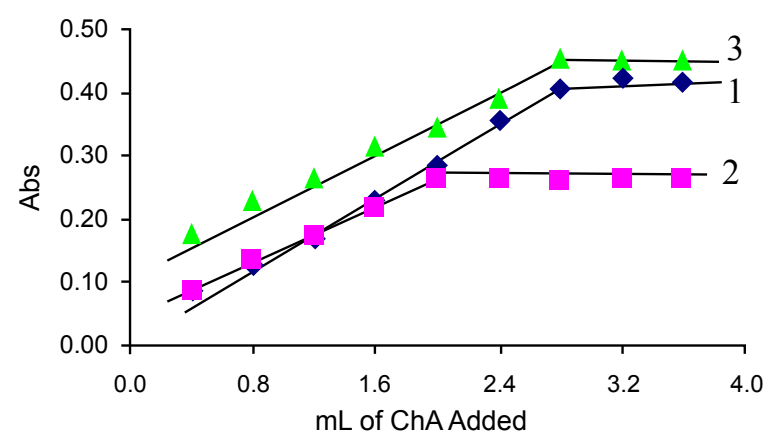

Figure 4: Effect of reagent concentration on ChA complexes with (1) ERY (15 $\left.\mu \mathrm{gL}^{-1}\right),(2) \operatorname{ROX}\left(12 \mu \mathrm{g} \mathrm{mL}^{-1}\right)$ and (3) CLR $\left(20 \mu \mathrm{g} \mathrm{m}^{-1}\right)$.

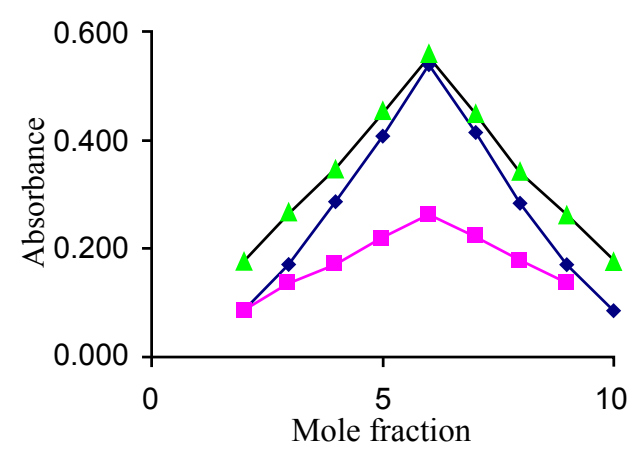

Figure 5: Job's plot for complexes of $\operatorname{ERY}(\bullet), \operatorname{ROX}(\boldsymbol{\bullet})$ and $\operatorname{CLR}(\boldsymbol{\Delta})$ with ChA.

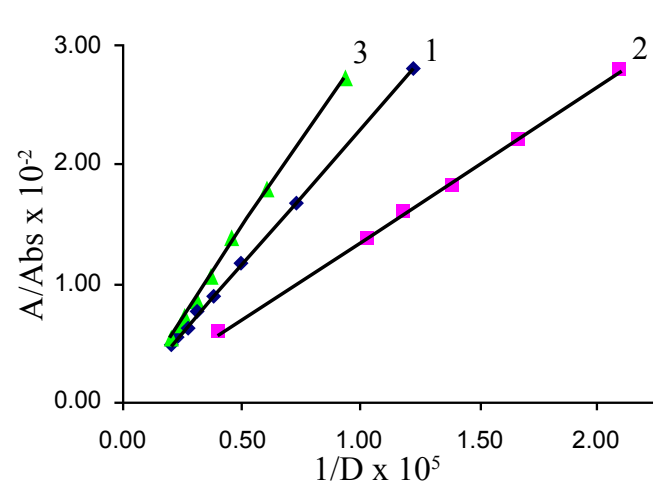

Figure 6: BH plot for complexes of (1) ERY, (2) ROX and (3) CLR with ChA.

molar absorptivity, limit of detection and quantitation are listed in Table 1 . The high values of molar absorptivity of the resulting colored complexes indicate the high sensitivity of the methods. High value of correlation coefficient confirms the best linearity of the calibration curve.

In order to study the accuracy and precision of the proposed method, five concentration of each drug within the linearity range were selected and analyzed. Precision of the method was evaluated by inter-day and intra-day percent relative standard deviation which was found to be in the range of $0.23-1.71,0.17-0.77$ and $0.07-0.38$ respectively. The results indicate that the methods have good repeatability and reproducibility (Table 2). Accuracy of the method was established in terms of percent recovery values and percent error in dosage formulation. The percent relative error was found to be in the range of 0.23-1.96, 0.18-0.52 and 0.04-0.28 respectively (Table 3 ).

\section{Sensitivity}

Limit of detection and quantitation were determined to establish the sensitivity of method. These were found to be $0.19,0.60,0.37$ and 0.59, 1.82, 1.12 for ERY, ROX and CLR respectively (Table 1 ).

\section{Interference of excipients}

Accurately weighed $10 \mathrm{mg}$ lactose monohydrate, microcrystalline cellulose, magnesium stearate, starch and talc were separately transferred into $50 \mathrm{~mL}$ volumetric flask and small amount of acetonitrile was added, the contents were sonicated for complete mixing, then the volume was finally brought to the mark with the same solvent and filtered. Aliquot of excipient solutions were spiked with drug solutions and absorbance were measured. The results were not affected in presence of commonly encountered excipients. Good recovery values (Table 4) obtained confirms the sensitivity of method.

\section{Application of the proposed method}

The proposed method was applied successfully for the determination of studied macrolides in commercial tablets by five replicate determinations. The results summarized in Table 3 , agree well with the proposed method confirming the good accuracy and precision of the method. Satisfactory recovery data in the range of 99.82-100.84, 99.40-101.86 and 99.37-99.72 indicated the reliability of method. Commonly present excipients did not found to interfere during the assay.

\section{Spectral characteristics}

From the absorption spectra of each complex, different spectral 


\begin{tabular}{|c|c|c|c|c|c|c|c|}
\hline Parameters & Linearity $\left(\mu \mathrm{gmL}^{-1}\right)$ & $\varepsilon_{\max } \times 10^{4}$ & Slope $\times 10^{-2}$ & Intercept & $\mathrm{R}^{2}$ & LOD $\left(\mu \mathrm{gmL}^{-1}\right)$ & $\mathrm{LOQ}_{\left(\mu \mathrm{gmL}^{-1}\right)}$ \\
\hline ERY-ChA & $3-36$ & 2.07 & 2.78 & 0.0032 & 0.9990 & 0.19 & 0.59 \\
\hline ROX-ChA & $4-40$ & 1.81 & 2.14 & 0.0034 & 0.9995 & 0.60 & 1.82 \\
\hline CLR-ChA & $8-40$ & 1.67 & 2.39 & -0.0226 & 0.9984 & 0.37 \\
\hline
\end{tabular}

Table 1: Analytical data for the reaction of the macrolides with ChA.

\begin{tabular}{|c|c|c|c|c|c|}
\hline Complex & Added $\left(\mu \mathrm{gmL}^{-1}\right)$ & Found $\left(\mu \mathrm{gmL}^{-1}\right)$ & $\% \operatorname{Rec}$ & $\%$ Err & $\%$ RSD \\
\hline \multirow{5}{*}{ ERY-ChA } & 3 & 3.06 & 101.96 & 1.96 & 1.71 \\
\hline & 6 & 6.01 & 100.23 & 0.23 & 0.23 \\
\hline & 10 & 10.10 & 101.04 & 1.04 & 0.95 \\
\hline & 15 & 15.08 & 100.54 & 0.54 & 0.56 \\
\hline & 27 & 27.09 & 100.33 & 0.33 & 0.42 \\
\hline \multirow{5}{*}{ ROX-ChA } & 6 & 5.97 & 100.34 & -0.52 & 0.50 \\
\hline & 8 & 7.97 & 99.48 & -0.35 & 0.77 \\
\hline & 10 & 9.98 & 99.65 & -0.18 & 0.35 \\
\hline & 12 & 11.94 & 99.82 & -0.49 & 0.17 \\
\hline & 14 & 13.95 & 99.51 & -0.35 & 0.58 \\
\hline \multirow{5}{*}{ CLR-ChA } & 8 & 8.01 & 100.17 & 0.17 & 0.15 \\
\hline & 12 & 12.00 & 99.96 & -0.04 & 0.07 \\
\hline & 16 & 16.03 & 100.18 & 0.18 & 0.19 \\
\hline & 20 & 20.06 & 100.28 & 0.28 & 0.38 \\
\hline & 24 & 24.04 & 100.18 & 0.18 & 0.16 \\
\hline
\end{tabular}

Table 2: Evaluation of accuracy and precision of the method in pure drug.

\begin{tabular}{|c|c|c|c|}
\hline Pharmaceutical preparations & Taken $(\mu \mathrm{g} / \mathrm{mL})$ & Found $(\mu \mathrm{g} / \mathrm{mL})$ & Mean $\%$ Rec \\
\hline \multirow{3}{*}{ Erythrocin $100 \mathrm{mg}$} & 15 & 15.03 & 100.45 \\
\cline { 2 - 4 } & 19 & 18.98 & 99.82 \\
\cline { 2 - 4 } & 23 & 23.14 & 100.84 \\
\hline \multirow{2}{*}{ Rulid@ $50 \mathrm{mg}$} & 8 & 8.23 & 101.82 \\
\hline \multirow{2}{*}{ Claritek $250 \mathrm{mg}$} & 12 & 12.37 & 101.86 \\
\cline { 2 - 4 } & 16 & 23.82 & 99.40 \\
\hline & 24 & 27.81 & 99.49 \\
\hline & 28 & 31.97 & 99.37 \\
\hline
\end{tabular}

Table 3: Recovery of macrolides in pharmaceutical formulations by the proposed method.

\begin{tabular}{|l|c|c|c|}
\hline Excipients & ERY & ROX & CLR \\
\hline Lactose monohydrate & 98.08 & 102.09 & 100.25 \\
\hline Microcrystalline cellulose & 99.27 & 101.98 & 98.54 \\
\hline Magnesium stearate & 99.52 & 101.96 & 98.71 \\
\hline Starch & 99.30 & 102.09 & 98.09 \\
\hline Talc & 99.54 & 99.78 & 101.24 \\
\hline
\end{tabular}

Table 4: Recovery of macrolides in presence of common excipients.

\begin{tabular}{|c|c|c|c|c|c|c|c|c|}
\hline Parameters & $\lambda_{\max }(\mathrm{nm})$ & $\mathrm{F}$ & $\mu$ & $\mathrm{IP}(\mathrm{eV})$ & $\mathrm{E}_{\mathrm{CT}}(\mathrm{eV})$ & $\mathrm{Rn}$ & $\mathrm{K}\left(\mathrm{L} \cdot \mathrm{mol}^{-1}\right)$ & $-\Delta \mathrm{G}^{\circ}(\mathrm{KCal})$ \\
\hline ERY-ChA & 498 & 11.18 & 34.39 & 8.83 & 2.50 & 0.71 & $2.07 \times 10^{3}$ & 7.54 \\
\hline ROX-ChA & 496 & 10.29 & 15.57 & 8.84 & 2.51 & 0.72 & $4.20 \times 10^{2}$ & 5.97 \\
\hline CLR-ChA & 491 & 11.95 & 35.31 & 8.88 & 2.53 & 0.72 & $2.14 \times 10^{2}$ & 5.30 \\
\hline
\end{tabular}

Table 5: Spectrophotometric results of macrolides-ChA complexes in ACN solvent at $25^{\circ} \mathrm{C}$.

characteristics were determined. Oscillator's strength (f) [27] and transition dipole moment $(\mu)$ [28] were calculated using the formulae $\mathrm{f}$ $=\left(4.319 \times 10^{-9}\right) \varepsilon_{\max } \cdot v_{1 / 2}$ and $\mu=0.0958\left(\varepsilon_{\max } \cdot v_{1 / 2} / \nu_{\max }\right)^{1 / 2}$. The ionization potential (Ip) of free donor [27] in acetonitrile medium was determined using the equation $I_{p}=5.76+1.53 \times 10^{-4} v_{C T}$. Resonance energy $\left(\mathrm{R}_{\mathrm{N}}\right)$ [29] and energy of charge transfer complexes $\left(\mathrm{E}_{\mathrm{CT}}\right)$ [30] were calculated by employing the equations $\varepsilon_{\max }=7.7 \times 10^{-4} /\left[\mathrm{h} v_{\mathrm{CT}} / \mathrm{R}_{\mathrm{N}}-3.5\right]$ and $\mathrm{E}_{\mathrm{CT}}=1243.667 / \lambda_{\mathrm{CT}}$, where $\varepsilon_{\max }$ is the molar extinction coefficient at maximum absorbance, $v_{1 / 2}$ is the band-width at half absorbance in $\mathrm{cm}^{-1}, v_{\max }$ and $v_{\mathrm{CT}}$ are wave number in $\mathrm{cm}^{-1}$ and $\lambda_{\mathrm{CT}}$ is the wavelength of charge transfer band. The obtained data is summarized in Table 5.
The association constant of the complexes (Table 5) was determined by using Benesi-Hildebrand equation [31], $\left[\mathrm{A}_{0}\right] / \mathrm{A}=1 / \mathrm{K}\left[\mathrm{D}_{0}\right] . \varepsilon+1 / \varepsilon$ for cells with $1 \mathrm{~cm}$ optical path length, where, $\left[\mathrm{A}_{0}\right]$ and $\left[\mathrm{D}_{0}\right]$ are the initial concentrations of the acceptor and donor respectively, $\mathrm{A}$ is absorbance of definite charge transfer band, $\varepsilon$ is molar extinction coefficient and $\mathrm{K}$ is the association constant. The concentration of acceptor is much greater then that of donor. On plotting the values of $\left[\mathrm{A}_{0}\right] / \mathrm{A}$ against $1 /$ $\left[D_{0}\right]$, sharp straight lines were obtained as shown in Figure 6. The data obtained throughout this calculation is given in Table 6 .

The standard free energy changes $\left(\Delta \mathrm{G}^{\circ}\right)$ associated with macrolides complexes were calculated from the association constants by applying 


\begin{tabular}{|c|c|c|c|c|c|}
\hline Complex & $\mathrm{D} \times 10^{-5}(\mathrm{M})$ & $\mathrm{A} \times 10^{-3}(\mathrm{M})$ & $\mathrm{Abs}$ & $1 / \mathrm{D} \times 10^{5}$ & $\mathrm{~A} / \mathrm{Abs} \times 10^{-2}$ \\
\hline \multirow{5}{*}{ ERY-ChA } & 0.81 & 4.78 & 0.1707 & 1.22 & 2.80 \\
\cline { 2 - 6 } & 1.36 & 4.78 & 0.2871 & 0.73 & 1.67 \\
\cline { 2 - 6 } & 2.04 & 4.78 & 0.4068 & 0.49 & 1.18 \\
\cline { 2 - 6 } & 2.59 & 4.78 & 0.5387 & 0.39 & 0.89 \\
\cline { 2 - 6 } & 3.10 & 4.78 & 0.6345 & 0.32 & 0.75 \\
\cline { 2 - 6 } & 3.60 & 4.78 & 0.7589 & 0.27 & 0.63 \\
\hline \multirow{5}{*}{ ROX-ChA } & 0.47 & 4.78 & 0.1720 & 2.09 & 2.78 \\
\cline { 2 - 6 } & 0.59 & 4.78 & 0.2167 & 1.67 & 2.21 \\
\cline { 2 - 6 } & 0.71 & 4.78 & 0.2621 & 1.39 & 1.82 \\
\cline { 2 - 6 } & 0.83 & 4.78 & 0.3009 & 1.19 & 1.59 \\
\cline { 2 - 6 } & 0.95 & 4.78 & 0.3465 & 1.04 & 1.38 \\
\cline { 2 - 6 } & 2.39 & 4.78 & 0.8211 & 0.41 & 0.58 \\
\hline & 1.07 & 4.78 & 0.0882 & 0.94 & 2.73 \\
\cline { 2 - 6 } & 1.60 & 4.78 & 0.1346 & 0.62 & 1.80 \\
\cline { 2 - 6 } & 2.14 & 4.78 & 0.1720 & 0.47 & 1.39 \\
\cline { 2 - 6 } & 2.67 & 4.78 & 0.2167 & 0.37 & 1.05 \\
\cline { 2 - 6 } & 3.21 & 4.78 & 0.2621 & 0.31 & 0.86 \\
\cline { 2 - 6 } & 3.74 & 4.78 & 0.3009 & 0.27 & 0.73 \\
\hline
\end{tabular}

Table 6: The values of $\left[A_{0}\right] / A b s$ and $1 /\left[D_{0}\right]$ for macrolides complexes.

equation [32] $\Delta \mathrm{G}^{\circ}=-2.303 \mathrm{RT} \log \mathrm{K}_{\mathrm{C}}$, where $\mathrm{R}$ is the gas constant $(1.987$ cal mol $\left.{ }^{-1} \mathrm{deg}^{-1}\right), \mathrm{T}$ is temperature in Kelvin and $\mathrm{K}_{\mathrm{c}}$ is the association constant of drug-acceptor complexes. The values of $\Delta \mathrm{G}^{\circ}$ are given in Table 5 .

\section{Conclusion}

The present work describes validated spectrophotometric methods based on charge transfer complexation for the determination of macrolides with ChA in bulk drug and in pharmaceutical formulations. The proposed method is simple, sensitive, inexpensive and reproducible for the determination of ERY, ROX and CLR. Spectral characteristics including oscillator's strength, dipole moment, ionization potential, energy of complexes, resonance energy, association constant and Gibb's free energy changes have been determined. The statistical parameters and the recovery data reveal good accuracy and precision of the methods. The method is free from interferences of the common excipients. Benesi-Hildebrand plots for each complex have been constructed.

\section{References}

1. Bekele LK, Gebeyehu GG (2012) Application of Different Analytical Techniques and Microbiological Assays for the Analysis of Macrolide Antibiotics from Pharmaceutical Dosage Forms and Biological Matrices. ISRN Analytical Chemistry 2012:17.

2. Flurer CL (1996) Analysis of macrolide antibiotics by capillary electrophoresis. Electrophoresis 17: 359-366.

3. Lalloo AK, Chattaraj SC, Kanfer I (1997) Development of a capillary electrophoretic method for the separation of the macrolide antibiotics, erythromycin, josamycin and oleandomycin. J Chromatogr B Biomed Sci Appl 704:333-341.

4. Khashaba PY (2002) Spectrofluorimetric analysis of certain macrolide antibiotics in bulk and pharmaceutical formulations. J Pharm Biomed Anal 27: 923-932.

5. El-Rabbat N, Askal HF, Khashaba PY, Attia NN (2006) A validated spectrofluorometric assay for the determination of certain macrolide antibiotics in pharmaceutical formulations and spiked biological fluids. J AOAC Int 89: 1276-1287.

6. Hedenmo M, Eriksson BM (1995) Liquid chromatographic determination of the macrolide antibiotics roxithromycin and clarithromycin in plasma by automated solid-phase extraction and electrochemical detection. J Chromatogr A 692: 161-166.

7. Dubois M, Fluchard D, Sior E, Delahaut P (2001) Identification and quantification of five macrolide antibiotics in several tissues, eggs and milk by liquid chromatography-electrospray tandem mass spectrometry. J Chromatogr B Biomed Sci Appl 753: 189-202.

8. Bahrami G, Mohammadi B (2007) Determination of clarithromycin in human serum by high-performance liquid chromatography after precolumn derivatization with 9-fluorenylmethyl chloroformate: application to a bioequivalence study. J Chromatogr B Analyt Technol Biomed Life Sci 850: 417-422.

9. Jiang Y, Wang J, Li H, Wang Y, Gu J (2007) Determination of clarithromycin in human plasma by liquid chromatography-electrospray ionization tandem mass spectrometry. J Pharm Biomed Anal 43: 1460-1464.

10. Feng YC, Hu CQ (2006) Construction of universal quantitative models for determination of roxithromycin and erythromycin ethylsuccinate in tablets from different manufacturers using near infrared reflectance spectroscopy. J Pharm Biomed Anal 41: 373-384.

11. Qu N, Li X, Dou Y, Mi H, Guo Y, et al. (2007) Nondestructive quantitative analysis of erythromycin ethylsuccinate powder drug via short-wave nearinfrared spectroscopy combined with radial basis function neural networks. Eur J Pharm Sci 31: 156-164.

12. Walash MI, Rizk MS, Eid MI, Fathy ME (2007) Spectrophotometric determination of four macrolide antibiotics in pharmaceutical formulations and biological fluids via binary complex formation with eosin [corrected]. J AOAC Int 90: 1579-1587.

13. Ashour S, Bayram R (2012) Novel spectrophotometric method for determination of some macrolide antibiotics in pharmaceutical formulations using 1 2-naphthoquinone-4-sulphonate. Spectrochim Acta A Mol Biomol Spectrosc 99:74-80.

14. Amin AS, Issa YM (1996) Selective spectrophotometric method for the determination of erythromycin and its esters in pharmaceutical formulations using gentiana violet. J Pharm Biomed Anal 14: 1625-1629.

15. Shah J, Jan MR, Manzoor S (2008) Extractive spectrophotometric methods for determination of clarithromycin in pharmaceutical formulations using bromothymol blue and cresol red. Journal of the Chinese Chemical Society 2:1107-1112.

16. Rao YS, Chowdary KPR, Seshagiriao JVLN (2003) A new spectrophotometric method for determination of clarithromycin in tablets. Int J Chem Sci 1:225-226.

17. Sultana N, Arayne MS, Abdul W (2011) Method Development and In vitro Interaction Studies of Verapamil in Presence, of Quinolones Using First Order Derivative UV Spectrophotometry and RP-HPLC Technique.J Chillean Chemical Society 56:848-855.

18. Najma Sultana, Saeed Arayne M, Saeeda Nadir Ali (2013) Charge transfer complexes of gama aminobutyric acid-analogue, a neurotransmitter: Synthesis and spectrophotometric determination. Journal of Bioanalysis and Biomedicine 5:013-021.

19. Siddiqui FA, Arayne MS, Sultana N, Mirza AZ, Qureshi F, et al. (2009) Facile and Manifest Spectrophotometric Methods for the Determination of Six Quinolone Antibiotics in Pharmaceutical Formulations using Iron Salts Medicinal Chemistry Research 19: 1259-1272.

20. Arayne MS, Sultana N, Zuberi MH, Siddiqui FA (2009) Spectrophotometric Quantitation of Metformin in Bulk Drug and Pharmaceutical Formulations using Multivariate Technique. Indian J Pharm Sci 71: 331-335.

21. Arayne MS, Sultana N, Bibi Z (2009) Rapid and Specific Spectrophotometric and RP-HPLC Methods for the Determination of Ascorbic Acid in Fruit Juices and in Human Plasma J Chemical Society of Pakistan 31: 402-407.

22. Arayne MS, Sultana N, Hussain F (2009) Spectrophotometric Method for the Determination of Montelukast in Bulk, Pharmaceutical Formulations and Human serum. J Anal Chemistry 64: 690-695.

23. Martinez JA, Horcajada JP, Almela M, Marco F, Soriano A et al. (2003) Addition of a macrolide to a ß-lactam-based empirical antibiotic regimen is associated with lower in-hospital mortality for patients with bacteremic pneumococcal pneumonia. Clin Infect Dis 36:389-395.

24. Tejedor F, Ballesta JP (1986) Reaction of some macrolide antibiotics with the ribosome. Labeling of the binding site components. Biochemistry 25: 7725 7731.

25. Basavaiah K, Charan VS (2002) The Use of chloranilic acid for the spectrophotometric determination of three antihistamines. Turk J Chem 26: 653-661.

26. Tang PH, Miles MV, Glauser TA, DeGrauw T (1999) Automated microanalysis of gabapentin in human serum by high-performance liquid chromatography with fluorometric detection. J Chromatogr B Biomed Sci Appl 727: 125-129. 
Citation: Sultana N, Saeed Arayne M, Ali SN (2013) The Use of Chloranilic Acid for the Spectrophotometric Determination of Three Macrolides through Charge Transfer Complex. Med chem 3: 241-246. doi:10.4172/2161-0444.1000146

27. Refat MS, El-Hawary WF, Moussa MA (2011) IR, 1H NMR, mass, XRD and TGA/DTA investigations on the ciprofloxacin/iodine charge-transfer complex. Spectrochim Acta A Mol Biomol Spectrosc 78: 1356-1363.

28. Aloisi GG, Pignataro S (1973) Molecular complexes of substituted thiophens with $s$ and $p$ acceptors. Charge transfer spectra and ionization potentials of the donors. J Chem Soc Faraday Trans 69:534-539.

29. Briegleb G, Czekalla J (1960) Intensity of electron transition bands in electron donator-acceptor complexes. Z Physik Chem(Frankfurt) 24:37-54.
30. Rathore R, Lindeman SV, Kochi JK (1997) Charge-transfer probes for molecular recognition via steric hindrance in donor-acceptor pairs. J Amer Chem Soc 119: 9393-9404.

31. Benesi HA, Hildebrand JH (1949) A spectrometric investigation of the interaction of iodine with aromatic hydrocarbons. J Am Chem Soc 71: 2703-2707.

32. Martin AN, Swarbrick J, Cammarata A (1969) Physical Pharmacy, (3rdedn), Lee \& Febiger, Philadelphia 344. 